\title{
ACCOUNTABILITY E O MOSAICO DA POLÍTICA DE AVALIAÇÃO DA EDUCAÇÃO SUPERIOR BRASILEIRA
}

http://dx.doi.org/10.5902/2318133834902

\author{
Alisson Slider do Nascimento de Paula ${ }^{1}$ \\ Frederico Jorge Ferreira Costa ${ }^{2}$ \\ Kátia Regina Rodrigues Lima ${ }^{3}$
}

\begin{abstract}
Resumo
Neste texto propõe-se a analisar os mecanismos que constituem o Sistema Nacional de Avaliação da Educação Superior - Sinaes -, sua articulação com a noção de accountability educacional de cunho técnico/contábil e a própria definição de qualidade adotado por este sistema avaliativo. No processo de investigação utilizou-se a abordagem qualitativa. Trata-se de uma pesquisa de tipo bibliográfica e documental. Considerou-se que o Sinaes utiliza diversos mecanismos para operacionalizar a avaliação, na qual sua centralidade está calcada no exame por desempenho como base dos processos regulatórios das instituições de educação superior, além da utilização de indicadores classificatórios, comparativos e escalonais para a sistematização de dados para a constituição de rankings entre as instituições.

Palavras-chave: accountability; Sinaes; qualidade; educação superior.
\end{abstract}

\section{ACCOUNTABILITY AND THE MOSAIC OF THE BRAZILIAN HIGHER EDUCATION EVALUATION POLICY}

\begin{abstract}
This text proposes to analyze the mechanisms that constitute the National System of Evaluation of Higher Education - Sinaes -, its articulation with the notion of educational/technical accountability and the definition of quality adopted by this evaluation system. In the research process the qualitative approach was used. This is a bibliographical and documentary research. It was considered that the Sinaes uses several mechanisms to operationalize the evaluation, in which its centrality is based on the performance examination as the basis of the regulatory processes of the institutions of higher education, besides the use of indicators and classificatory, comparative and staggered parameters for the systematization of data for the constitution of rankings among institutions, but without precisely defining the quality being evaluated.
\end{abstract}

Key-words: accountability; Sinaes; quality; higher education.

${ }^{1}$ Centro Universitário Inta, Brasil. E-mail: alisson.slider@yahoo.com.

2 Universidade Estadual do Ceará, Brasil. E-mail: fredericoo@uece.br.

3 Universidade Regional do Cariri, Brasil. E-mail: kareli2004@yahoo.com.

\begin{tabular}{l|l|l|l|l|l|}
\hline Regae: Rev. Gest. Aval. Educ. & Santa Maria & v. 8 & n. 17 & Pub. contínua 2019 & p. 1-15
\end{tabular}




\section{Introdução}

L m meados da década de 1990 uma onda avaliadora ganhou expressão no discurso oficial em função das redefinições do papel do aparelho estatal sob a racionalidade neoliberal, além de suas metamorfoses sob o viés da terceira via. É lícito ressaltar que o tipo de avaliação que surgia calcava-se numa lógica de accountability já bastante utilizada pelos países centrais, além de sua própria irradiação pelo espaço global dos Estados-nações já apregoada pelos organismos internacionais.

Esta racionalidade atingiu a educação superior que, no contexto nacional, incorporou uma miríade de políticas e mecanismos que constituíram o Sistema Nacional de Avaliação da Educação Superior - Sinaes -, buscando definir e avaliar a qualidade da educação superior no Brasil em todas as suas instâncias administrativas. Nesse panorama, a noção de avaliação baseada numa racionalidade de accountability estaria disposta a efetivar um processo comprometido com os interesses públicos? A racionalidade técnica em ascensão, em especial a partir da década de $1990^{4}$, apropria-se do processo de regulação e supervisão da educação superior?

Responder a esses questionamentos põem-se na ordem do dia, contudo, não se trata de uma tarefa das mais simples. A avaliação da educação superior na história recente do Brasil vivenciou diversas metamorfoses, expondo avanços e recuos do ponto de vista operacional. Todavia, não se pretende aqui desenvolver um resgate histórico dos procedimentos avaliativos deste nível de ensino, contudo, o Sinaes ganhou destaque por ser um programa que traz, em sua origem, princípios baseados no Programa de Avaliação Institucional das Universidades Brasileiras - Paiub -, e que no decurso de sua operacionalidade sofreu metamorfoses, tanto na forma, quanto em seu conteúdo.

A finalidade deste texto é analisar os mecanismos que constituem o Sinaes, sua articulação com a noção de accountability educacional de cunho técnico e contábil e a própria definição de qualidade adotado por este sistema avaliativo. O presente texto expõe algumas considerações acerca da noção de accountability educacional, os impasses na definição de qualidade para a educação superior, além do próprio aparato político-jurídico orquestrado para efetuar a processualidade avaliativa hodierna que se expressa pelo Sinaes.

\section{O avanço da noção de accountability educacional no seio da reforma do Estado avaliador}

A ascensão de concepções neoconservadoras e neoliberais provocou alterações consideráveis nas engrenagens do sistema de organização social. As reformas empreendidas pelos governos Thatcher (1979-1990) e Major (1990-1997), na Inglaterra, efetuaram a descentralização dos serviços voltados ao aspecto social, áreas como saúde e educação foram caracterizadas como dispendiosas. Nessa acepção, ajustes econômicos foram implementados tendo em vista a nova racionalidade que se irradiava numa escala global. Em acréscimo, a noção do New Labour foi engendrada na gestão de Blair (1997-2000), o sentido de participação popular como um dos princípios de fomento do terceiro setor que se apresentava como alternativa às privatizações operadas no início

\footnotetext{
${ }^{4}$ A ênfase dada a partir da década de 1990 se dá em função de atender os intentos neoliberais, sobretudo, a partir da irradiação de sua concepção no Brasil nesse período.

\begin{tabular}{|l|l|l|l|l|l|} 
Regae: Rev. Gest. Aval. Educ. & Santa Maria & v. 8 & n. 17 & Pub. contínua 2019 & p. $1-15$ \\
\hline
\end{tabular}
} 
da noção neoliberal tornava-se central em seu discurso. A Terceira Via ${ }^{5}$ surgiu com intuito de superar as crises do Estado pelo fortalecimento na relação entre as instituições da sociedade civil.

Com efeito, a busca dos governos em obter maior apoio popular propiciou o ensejo para as organizações não governamentais, bem como empresas com interesses de benefício pela sua responsabilidade social a participarem dessa processualidade, decorrendo, destarte, na maior aprovação e participação popular. Na verdade, "o novo modelo de administração pública apelava para os slogans da cidadania ativa e do empoderamento das comunidades, conquistando, assim, adesão popular às modificações em curso na sociedade britânica" (Shiroma; Santos, 2014, p. 23).

É lícito ressaltar que se buscou, até aqui, tratar de expor, no campo político, a implantação da noção de terceira via na sociedade britânica. A partir desse movimento compreende-se o alastramento dessas concepções em diversos locais no globo. No Brasil a reforma do Estado aconteceu no interior de um processo complexo, no qual permearam concepções político-ideológicas diversas e por vezes antagônicas, que na esteira das relações sociais se mostram como verdadeiros obstáculos para os setores populares.

Em 1995, pelo Ministério da Administração e Reforma do Estado, a reforma do Estado foi pensada em efetuar a estabilização fiscal juntamente com o crescimento econômico de modo sustentável. Na concepção do Plano Diretor da Reforma do Aparelho do Estado esta reforma envolve quatro problemas distintos, todavia, interdependentes:

(a) um problema econômico-político - a delimitação do tamanho do Estado; (b) um outro também econômico-político, mas que merece tratamento especial - a redefinição do papel regulador do Estado; (c) um econômicoadministrativo - a recuperação da governança ou capacidade financeira e administrativa de implementar as decisões políticas tomadas pelo governo; e (d) um político - o aumento da governabilidade ou capacidade política do governo de intermediar interesses, garantir legitimidade, e governar. (Pereira, 1997, p. 7)

Nesse sentido, na definição do tamanho do Estado, surgiam-se três pilares que orientariam o processo de reforma do Estado: privatização, publicização e terceirização. No plano econômico a crise recebeu uma interpretação de crise fiscal em decorrência da ineficiência da gestão e dos serviços públicos. A superação dessa crise foi pautada em estratégias com grande aproximação com os princípios adotados na reforma estatal britânica, a saber: "críticas à burocracia do Estado; proposta de administração pública voltada aos resultados; implementação de uma gestão gerencial baseada na eficiência, descentralização e participação da comunidade" (Shiroma; Santos, 2014, p. 24).

Os reformadores denotaram uma forte crítica à lentidão dos serviços oferecidos pelo Estado em sua estrutura burocratizada e a rigidez do andamento do funcionalismo público, pois foram considerados como obstáculos ao desenvolvimento da nação. Os critérios que foram utilizados para orientar a administração gerencial para combater esses obstáculos foram: eficiência, eficácia, liderança e avaliação de desempenho.

\footnotetext{
${ }^{5}$ A noção de Terceira Via não ultrapassa os limites do neoliberalismo, essa racionalidade desenvolve um discurso que alcança os setores sociais, contudo, o seu conteúdo ainda está atrelado à racionalidade financeira em que a privatização ganha destaque em detrimento do setor e dos interesses públicos.

\begin{tabular}{|l|l|l|l|l|l|}
\hline Regae: Rev. Gest. Aval. Educ. & Santa Maria & v. 8 & n. 17 & Pub. contínua 2019 & p. 1-15
\end{tabular}
}


Nesse contexto, o Estado mantém seu protagonismo, contudo, é modificado para garantir uma regulação que torne exequível o controle mediante o elo envolvendo financiamento-fornecimento-regulação (Afonso, 1999). Com efeito, no que concerne o campo educacional, esse controle estatal se realiza através da inserção de currículos nacionais, bem como testes padronizados.

Afonso (1999), para elucidar esse processo, baseia-se em Mary Henkel e contextualiza as políticas no contexto britânico de ascensão do New Labour: "O governo identificou a avaliação como um componente significativa na sua trajetória de conseguir alguns objetivos decisivos: controlar as despesas públicas, mudar a cultura do setor público e alterar as fronteiras e a definição das esferas de atividade pública e privada" (Henkel, 1991 apud Afonso, 1999, p. 140).

Compreende-se, deste modo, avaliação como instrumento para aferição de resultados em detrimento da reflexão acerca do processo. Nesse itinerário analítico, surge a ascensão da noção de accountability, esta noção, consoante Maroy (2013, p. 320), "tende a ser sinônimo de novas formas de regulação baseadas nos resultados que se propõem a substituir ou sobrepor as regulações burocrático-profissionais predominantes até o momento". Estas novas formas de regulação se tratam de dispositivos de avaliação do desempenho das instituições, na referida pesquisa tratar-se-á das instituições de ensino superior. Este desempenho centra-se nos objetivos curriculares denotados pelas diretrizes curriculares nacionais para formação profissional. Com efeito, este tipo de avaliação possibilita sanções que visam ajustar as IES, bem como suas práticas para qualificarem seus resultados nas avaliações.

A conceituação de accountability pode obter diversos significados em função da noção e contexto sócio-político no qual esteja traduzindo. Na verdade, em virtude dos vários trabalhos que tematizam a accountability, observa-se a dificuldade centrada na sua tradução, nessa acepção, compreende-se que não há um significado único que represente a accountability. Percebe-se, deste modo, diferentes traduções sobre o termo, contudo, obtêm-se sentidos próximos. Isto é, "a palavra accountability tem sido comumente traduzida como responsabilização" (Pinho; Sacramento, 2009, p. 1345).

Utilizando como referência alguns estudiosos sobre a relação accountability e educação (Maroy, 2006; 2013; Broadfoot, 2000; Carnoy; Loebb, 2002), a accountability educacional poder ser compreendida em dois movimentos: diagnóstico e contabilização. Esses dois movimentos buscam identificar e contabilizar o desempenho dos sistemas de educação tendo por base os objetivos estabelecidos previamente. Esse processo utilizase, também, como mecanismos de controle e reparo das falhas diagnosticadas entre objetivos e resultados. Nesse sentido, a accountability na educação tende-se a expressarse como avaliação externa, levando em conta as experiências dos alunos, bem como as práticas educacionais.

A accountability sob a lógica da responsabilização nos remente ao sentido de prestação de contas, assim, a IES deve prestar contas com o Estado, que exerce função de regulador, isto é, Estado-avaliador, nesse sentido, a prestação de contas da IES se realiza através de uma avaliação de desempenho. No limite, accountability na educação 
se trata de constituir mecanismos de regulação calcados em saberes que possibilitem avaliação de resultados de aprendizagens estabelecidas e previamente denotadas nas diretrizes curriculares, além de garantir o controle do processo que se refere aos padrões de qualidade.

Com efeito, os mecanismos de prestação de contas das IES, isto é, de accountability, participam do regime de regulação pós-burocrático dos sistemas educativos, baseados nos postulados do Estado avaliador. A accountability trata-se de uma manifestação do paradigma econômico. Através dos resultados mensuráveis possibilita-se a competição e concorrência entre serviços educacionais, além da escolha dos consumidores. Sendo assim, este cenário se trata de um modelo de responsabilização baseado na lógica do mercado.

Essa lógica de avaliação é inerente à noção do Estado avaliador que se efetua no processo de regulação estatal, definindo, assim, políticas educativas para os sistemas de ensino com ênfase no controle das competências introduzidas nos currículos de cursos de nível superior, bem como seus resultados. Estes resultados, por seu turno, são utilizados para orientar onde o mercado educacional deverá agir.

No Brasil, o Estado avaliador está atrelado à ascensão da racionalidade neoliberal a partir dos anos de 1990, bem como na irradiação da noção da Terceira via pós década de 1990. No limite, os governos que conduziram seus mandatos desde o início dessa racionalidade, seguiram orientações do Consenso de Washington e dos organismos internacionais para efetivarem medidas draconianas de privatização do patrimônio público, desregulação da economia, ajuste fiscal, liberalização financeira, abertura comercial, estabelecimento de parcerias público-privadas e sua consequente diluição da noção público/estatal e privado/mercantil, dentre outros.

\section{O impasse da definição da qualidade na política de avaliação educacional brasileira}

A política de avaliação educacional se tornou temática de grandes debates na área da educação decorrendo na constituição da avaliação como estratégia política de supervisão e controle do sistema de ensino. É lícito considerar que a temática acerca da política de avaliação educacional permeia um predominante horizonte técnico/contábil e econômico, sua organização reside no afastamento da participação popular e na desconsideração dos saberes culturais históricos e culturalmente constituídos. Destarte, "o que traduziria a avaliação em mero controle contábil ao invés da auto-regulação e controle social” (Souza, 2009, p. 17).

No contexto do Estado avaliador e da accountability educacional a avaliação assume a condição de mecanismo estratégico calcado em três bases indissociáveis para a racionalidade técnica: eficiência, eficácia e avaliação de desempenho. Nessa acepção, a racionalidade neoliberal se expressa via Estado avaliador a partir de uma noção reguladora, isto é, de privatização que, por seu turno, está calcada no predomínio das competências e da superioridade da eficiência do setor privado/mercantil sobre as ações coletivas. Essa racionalidade estende-se à educação, em especial a educação superior que, partir da promulgação da Lei de Diretrizes e Bases da Educação Nacional (Brasil, 1996a) e do decreto n. 2.207, de 15 de abril de 1997 (Brasil, 1997) passa a ser compreendida como um negócio a ser tratado no mercado do setor de serviços. 
No que concerne à educação superior brasileira, foi no contexto da reforma desencadeada ainda na década de 1990 que se empreendeu uma vasta expansão das instituições privadas de educação superior. No início dos anos 2000 efetivou-se uma reforma de outra roupagem ${ }^{6}$. Foi pelo discurso do mercado livre que houve uma grande intensificação na criação das instituições privadas de educação superior guiadas pela desregulamentação. Nesse contexto, a falta de supervisão pública possibilitou a oferta de serviços educacionais de qualidade contestável via mercantilização. Esse processo decorre na formulação de uma função reguladora que o Estado assumiu municiando-se de políticas públicas para efetivar o intento de fiscalizar, supervisionar e controlar (Rothen; Barreyro, 2009).

As instituições privadas de educação superior orientadas para o mercado tem seu direcionamento voltado para a massificação, com isso, compreende-se que há uma queda na qualidade quando vender o pacote/curso de forma mais fácil e que se encaixe na rotina do aluno/cliente são slogans irradiados pelas próprias instituições ganharam prioridade em detrimento da formação profissional em que o ensino, pesquisa e extensão sejam a base indissociável da formação. Nesse contexto, sistemas de garantia de qualidade foram criados para consolidar a lógica da regulação estatal. A garantia de qualidade ficou a cargo das agências para efetivar essa finalidade do Estado.

Nessa acepção, para se definir os níveis mínimos de qualidade, necessita-se definir o que seria essa qualidade. Compreende-se que não se trata de um conceito de fácil definição, em função dos valores subjetivos e conjunturais inerentes a cada contexto social que se estabelece um padrão de qualidade. No que diz respeito à qualidade da educação superior, Dias Sobrinho (2000) compreende esse tipo de qualidade como algo valorativo e constituído socialmente, ou seja, "um atributo ou um conjunto de propriedades que definem uma coisa e a distinguem das demais, de acordo com julgamentos de valores praticados num determinado meio" (p. 212).

Em acréscimo, para definição dessa noção de qualidade necessita-se de elementos comparativos, pois esse tipo de valor inerente ao sentido de uma qualidade particular não se trata de um valor abstrato selecionado aleatoriamente, contudo, trata-se de um tipo de valor constituído socialmente em que possa ter elementos comparativos. Com efeito, esse tipo de valor deve ser selecionado por cada instituição, dessa forma, poderá ser avaliado pelo setor externo. Nesse processo há um sistema de valor que será mais apreciado que outro em termos comparativos por se tratar de uma tomada de posição, isto implica 0 meio social no qual o setor externo representa.

Devido a irradiação da racionalidade neoliberal grandes consequências foram acarretadas para o processo de regulação, pois os padrões de qualidade que se tornaram referências para as políticas de avaliação condicionaram o modelo da educação superior. Busca-se, na nova organização institucional, reduzir a intervenção regulatória estatal ao máximo através da criação das agências independentes para regular vários serviços que outrora eram regulados pelo Estado.

\footnotetext{
${ }^{6}$ A reforma da educação superior nos governos Lula da Silva e Dilma Rousseff, empreendeu-se uma lógica de agradar gregos e troianos, isto é, os setores hegemônicos - financeiro, agronegócio e commodities - e os setores populares. Todavia, para Oliveira (2010), esse movimento, em verdade, empreendeu o fenômeno chamado de hegemonia às avessas, que a despeito das políticas direcionadas para as camadas populares, no limite, havia um conteúdo arraigado com o setor empresarial.

\begin{tabular}{l|l|l|l|l|r|} 
Regae: Rev. Gest. Aval. Educ. & Santa Maria & v. 8 & n. 17 & Pub. contínua 2019 & p. $1-15$
\end{tabular}
} 
Com efeito, a política de avaliação condiciona o modelo e a lógica da educação superior brasileira,

a avaliação da educação nacional, ao contrário do que se percebe à primeira vista, não está restrita ao terreno pedagógico. Ela reflete orientações políticas dos governos e, muitas vezes, perde seu caráter de diagnóstico de situações a serem aperfeiçoadas para tornar-se instrumento de controle do Estado. [...] esse quadro não se restringe ao Brasil, mas a todos os países capitalistas, periféricos ou centrais [...] Dá-se a ênfase à avaliação por resultados (e produtos), e, consequentemente, desvalorizase a avaliação dos processos, como é o caso dos exames nacionais que reduzem a complexidade do processo educativo apenas ao que é mensurável. É preciso definir se a avaliação será instrumento de controle ou de desenvolvimento, de promoção do ser humano e da escola. (Souza, 2009, p. 20)

Questiona-se, nessa acepção, a avaliação está a serviço de quem? Seria do aumento do poder estatal em controlar via regulação? A partir do que já foi exposto, percebe-se que a avaliação não se trata de um instrumento de diagnóstico de problemas e lacunas na formação profissional dos estudantes do ensino superior, e nem denota soluções para corrigi-las. No limite, a implementação do Sistema Nacional de Avaliação da Educação Superior determina a questão da qualidade como objeto central a melhoria da qualidade. Sendo assim, faz-se necessário empreender uma análise acerca do marco legal da avaliação da educação superior brasileira buscando desvelar o caráter de sua processualidade e os padrões de qualidade definidos por seu sistema.

\section{O mosaico da política de avaliação da educação superior brasileira e seus apontamentos para a predominância da regulação}

No decurso histórico da avaliação da educação superior brasileira, diversas foram as experiência que se desdobraram, contudo, a presente análise centra-se a partir do ano de 1993, com a implementação do Programa de Avaliação Institucional das Universidade Brasileiras, por se tratar do primeiro programa que se pretendeu avaliar a educação superior em escala nacional, não obstante as experiências anteriores: Programa de Avaliação da Reforma Universitária, constituído em 1983; o desenvolvimento em 1985 do relatório da Comissão Nacional de Reformulação da Educação Superior; além do próprio relatório do Grupo Executivo para a Reformulação da Educação Superior em 1986 (Lacerda; Ferri; Duarte, 2016).

A lei n. 9.394/96 e o decreto n. 2.026/96 (BRASIL, 1996b) implementaram alterações na dinâmica do Paiub que se pretendia um programa abrangente, de base sistemática e de processualidade contínua. Em acréscimo, foi estabelecido indicadores de avaliação de desempenho das IES, bem como dos cursos de graduação e pós-graduação, além do do Exame Nacional de Cursos - ENC. Os apontamentos a serem observados na avaliação foram explicitados pelo secreto n. 3.860/01 (Brasil, 2001). Essa lógica foi completada com a implantação do Censo da Educação Superior.

Em 2002 como proposta 12 para a educação superior do programa de governo de Lula da Silva, surgiu o Sistema Nacional de Avaliação da Educação Superior - Sinaes. Esta proposta buscava "rever o atual sistema de avaliação que inclui o Exame Nacional 
de Cursos - ENC ou Provão - e implantar um sistema nacional de avaliação institucional a partir, entre outras, da experiência do Programa de Avaliação das Universidades Brasileiras" (Programa de Governo de Lula da Silva, 2002).

Ristoff e Giolo (2006) expõem análise precisa acerca da Proposta 12 e sua indicação sobre os processos avaliativos antecedentes. Conforme os autores,

a proposta 12, por sua vez, indica com precisão seus antecedentes: entre outras, a experiência do Programa de Avaliação Institucional das Universidades Brasileiras (Paiub). Essas outras experiências de que fala a Proposta são, principalmente, o processo de avaliação criado e consolidado pela Coordenação de Aperfeiçoamento de Pessoal de Nível Superior (Capes), a partir de 1976; o Programa Executivo para a Reforma da Educação Superior (Geres), instituído em 1985; o Exame Nacional de Cursos (ENC); a Avaliação das Condições de Oferta/Ensino, e a Avaliação de Centros Universitários, implantados em 1996. (p.194)

Nesse sentido, a constituição do Sinaes representou a retomada de experiências, metas e objetivos mais significativos para a educação superior brasileira. Ora, isto aconteceu em função do Sinaes pela lei n. 10.861, de 14 de abril de 2004 (Brasil, 2004), tê-lo transformado em política de Estado. A base da experiência denotada para o Sinaes baseia-se no Paiub. O Sinaes, no início, incorporou em sua lógica princípios e diretrizes do Paiub, entre eles, ressalta Ristoff e Giolo (2006), o "compromisso formativo da avaliação, a globalidade, a integração orgânica da auto-avaliação com a avaliação externa, a continuidade, a participação ativa da comunidade acadêmica, o respeito à identidade institucional e o reconhecimento da diversidade do sistema" (p. 197). Todavia, - Sinaes não incorporou o princípio da adesão voluntária. Em função de se tratar de uma política de Estado, todas as IES do país participam dos processos avaliativos que compõem o sistema Sinaes. É oportuno ressaltar a necessidade de constituir comissões próprias de avaliação, comissões com autonomia na auto-avaliação institucional. No limite, os dados dos resultados do Sinaes são públicos, em função de sua transparência, estabelecida por lei.

O processo de reorganização da avaliação da educação superior representou engendrar um sistema em que novos mecanismos e critérios fossem destacados para que tornasse exequível suprimir o sistema fragmentado em prol da construção de um sistema orgânico de avaliação, possibilitando, inclusive, estabelecer o elo entre auto-avaliação e avaliação externa.

A constituição do Sinaes baseia-se na noção de que todas as avaliações da educação superior, geridas pelo Ministério da Educação, estejam sistematizadas e desdobrem doravante a ideia que articule os momentos, metodologias, bem como os instrumentos de avaliação e de informação. Pelo Sinaes toda avaliação da educação superior, com exceção da pós-graduação stricto sensu regida pelo modelo Capes de avaliação, ficaram sob tutela do Inep, orientadas pelos apontamentos da Comissão Nacional de Avaliação da Educação Superior - Conaes -, servindo como base para diversos órgãos do MEC efetivarem suas funções regulatórias. Com o Sinaes, buscou-se separar avaliação da regulação, apesar de uma ser o fundamento da outra. 
Art. $2^{\circ}$ - O Sinaes, ao promover a avaliação de instituições, de cursos e de desempenho dos estudantes, deverá assegurar: I - avaliação institucional, interna e externa, contemplando a análise global e integrada das dimensões, estruturas, relações, compromisso social, atividades, finalidades e responsabilidades sociais das instituições de educação superior e de seus cursos; II - o caráter público de todos os procedimentos, dados e resultados dos processos avaliativos; III - o respeito à identidade e à diversidade de instituições e de cursos; IV - a participação do corpo discente, docente e técnico administrativo das instituições de educação superior, e da sociedade civil, por meio de suas representações. Parágrafo único. Os resultados da avaliação referida no caput deste artigo constituirão referencial básico dos processos de regulação e supervisão da educação superior, neles compreendidos o credenciamento e a renovação de credenciamento de instituições de educação superior, a autorização, o reconhecimento e a renovação de reconhecimento de cursos de graduação. (Brasil, 2004)

O Sinaes instituiu a avaliação em três instâncias: instituição, curso e estudantes. Para que as informações fossem mais explícitas, foi previsto por lei que as instâncias não seriam independentes (Rothen; Barreyro, 2009). Para ressaltar a missão da educação superior, foi declarado que a finalidade da avaliação seria a melhoria da qualidade (Brasil, 2004). Como mencionado acima, a questão da qualidade, na proposta do Sinaes, trata-se de um objetivo central:

O Sinaes tem por finalidades a melhoria da qualidade da educação superior, a orientação da expansão da sua oferta, o aumento permanente da sua eficácia institucional e efetividade acadêmica e social e, especialmente, a promoção do aprofundamento dos compromissos e responsabilidades sociais das instituições de educação superior, por meio da valorização de sua missão pública, da promoção dos valores democráticos, do respeito à diferença e à diversidade, da afirmação da autonomia e da identidade institucional. (Brasil, 2004)

O Sinaes constitui-se por três componentes essenciais: avaliação das instituições, dos cursos e do desempenho dos estudantes. Ainda, sua avaliação permeia a responsabilidade social da IES, a gestão institucional, a infraestrutura, o corpo docente, o desempenho do estudo, além de outros aspectos que envolvem ensino, pesquisa e extensão.

Canan e Eloy (2016) refletem sobre as implicações dos resultados para traçarem um padrão de qualidade para as IES brasileiras, isso só se torna exequível em virtude da coordenação e supervisão da Conaes, contudo, a etapa operacional fica sob responsabilidade do Inep. No que concerne à avaliação dos estudantes o Exame Nacional de Desempenho dos Estudantes é constituído em duas partes: 10 questões de conhecimentos gerais e 30 questões de formação específica. O conceito Enade é sistematizado em cinco níveis, além de sua lógica ser diversa ao Provão, uma vez que a quantidade de questões do Enade segue um padrão único para todas as áreas de formação. O Indicador de Diferença entre os Desempenhos Observados e Esperados IDD -, criado em 2005, objetiva verificar o conhecimento irradiado aos estudantes pelas IES. Para Rothen e Barreyro (2014), esse indicador é a justificativa das instituições privadas em função do desempenho satisfatório de algumas IES em função de receberem bons alunos. 
O ciclo do Sinaes teve morosidade, decorrendo na edição de várias portarias em função do reconhecimento temporário de cursos em função da necessidade de emissão de diplomas para os concluintes. Além disso, o processo de reconhecimento de cursos e credenciamento de instituições viu-se prejudicado em virtude de dois fatores: 1) a reivindicação das IES acerca das taxas pagas ao Inep para a realização desse processos; 2) O veto ao pagamento do prolabore dos professores de IES públicas com dedicação exclusiva que realizavam avaliação in loco, realizado pelo Tribunal de Contas da União. Essa conjuntura exigiu medidas legais que se torna factível a continuidade do processo de regulação e credenciamento das IES (Rothen; Barreyro, 2014). Nessa acepção, em 2006, realizou-se a edição do decreto n. 5.773/06 (Brasil, 2006), definindo, por seu turno, os procedimentos para regulação, supervisão, além das atividades encaminhadas à diversos órgãos, enfatizando, deste modo, a fiscalização da educação superior brasileira.

A supervisão da educação superior centrou-se na utilização dos resultados do Enade como indicadores para a visita in loco de especialistas. Assim, para efetivar a renovação de reconhecimento de cursos, em 2007, foi anunciado um conceito preliminar para tornar possível a efetivação desse processo, que só veio a acontecer em $2008 \mathrm{com}$ a criação o Conceito Preliminar de Curso - CPC - pela edição da portaria normativa n. 40 (Brasil, 2007).

O CPC, por sua vez, conforme a portaria n. 40/07, iria compor-se via resultados do Enade e dos dados do Censo da Educação Superior. É lícito ressaltar a relevância do Enade na processualidade da avaliação da educação superior brasileira. O Enade, conforme Canan e Eloy (2016), configura-se para além somente de um instrumento de avaliação, contudo, seus resultados tornam exequível a organização de rankings entre cursos e IES brasileiras. Este tipo de avaliação em larga escala condiciona a reformulação curricular dos cursos de graduação, influenciam gestão de cursos a busca de resultados positivos, implicando, deste modo, em estratégias para preparação do estudante.

A busca pelo melhor desempenho do aluno no Enade, evidencia o afinamento da política de avaliação da educação superior aos intentos dos organismos internacionais no contexto da globalização e de expansão financeira do capital:

Essa cobrança implica resultados numéricos e prioriza a busca pela eficiência e pela qualidade diante das demandas sociais. Desse modo, a avaliação externa, instituída pelo Ministério da Educação, utiliza-se de testes padronizados para medir o nível de conhecimentos dos acadêmicos no final dos cursos, deixando, muitas vezes, de valorizar o processo de ensino-aprendizagem e a produção cultural, científica, tecnológica e de formação cidadã (Canan; Eloy, 2016, p. 623)

Não obstante uma miríade de elementos e políticas em volta do Sinaes, é necessário dar ênfase na dinâmica do Enade por se tratar de um modelo de avaliação que se afina com a predominância técnica/contábil avaliativa global que permeia as instituições de ensino. O Enade se trata de um exame de conhecimentos específicos 
aplicados à estudantes concluintes de todos os cursos que são avaliados no ano em vigência. Através dos resultados do Enade, o CPC e o Índice Geral de Cursos - IGC -7, os dados são sistematizados para a constituição de rankings pelos meios de comunicação.

A constituição de rankings com a IES que participaram do Enade pelos conceitos conferidos a elas, configura-se como uma política de avaliação já utilizada em escala global, isto é, uma política semelhante ao Programa Internacional de Avaliação de Estudantes - Pisa. A despeito de se tratar de uma avaliação externa, essa lógica se mostra frágil por não apresentar um caráter contínuo com os estudantes em avaliação.

Nessa acepção, apesar do Sinaes buscar constituir todo um sistema que forneça bases para avaliar a IES nos aspectos referentes a pesquisa, extensão, infraestrutura, bem como o próprio processo de avaliação institucional, via a criação das CPA's, a criação do CPC e do IGC se evidencia como breve exemplo de modelo de regulação que vai na contramão dos princípios do Sinaes. A constituição e divulgação do ranqueamento das IES brasileiras pela mídia, foi visto pelos especialistas que sistematizaram a lógica da implantação do Sinaes como sistema, como uma verdadeira negação da essência do Sinaes.

Os índices CPC e IGC oriundos do Enade implicam uma lógica de comparabilidade e simplificação dos processos avaliativos, sobressaindo, deste modo, a lógica da regulação sobre a avaliação. Nos índices que são utilizados pelo Sinaes o quesito desempenho expressa superioridade diante dos demais, isto é, representa $55 \%$ da nota. Este desempenho é expresso pelo Enade e pelo IDD. Nessa acepção, o conceito de qualidade é reduzido a mensuração do desempenho estudantil. Com isso, essa ênfase dada ao desempenho se caracteriza como um processo de accountability, pondo a regulação sobre a avaliação.

Em 2017, pela nota técnica n. $16 / 2017^{8}$, o Inep adotou novos instrumentos para a efetivação da avaliação externa que atuaram no monitoramento da qualidade dos cursos de graduação nas modalidades presencial e a distância, assim como da qualidade das próprias IES. Essa nota técnica regulamenta os mecanismos de competência do Inep alusivos à avaliação das IES, dos cursos de graduação e do desempenho dos estudantes. No limite, estes instrumentos começaram a ser utilizados em 2018, complexificando os processos de avaliação, porquanto a predominância centra-se na lógica da regulação, isto é, da prestação de contas, pois os novos instrumentos direcionam sua finalidade na busca do rendimento e da instrumentalização em detrimento dos formatos emancipatórios de avaliação.

Nessa acepção, as concepções neopragmáticas catalisam os mecanismos operacionais da sociedade para uma lógica mercantil em que competição, eficiência, eficácia e padrão de qualidade são bases para seu status quo. No limite, a noção de racionalidade técnica infunde o sistema de regulação e supervisão da educação superior brasileira utilizando a justificativa de uma provável avaliação de sua qualidade.

7 O Índice Geral de Cursos foi implantado pela portaria normativa n. 12, de 5 de setembro de 2008 (Brasil, 2008).

8 Coordenação Geral de Avaliação dos Cursos de Graduação e Instituições de Ensino Superior, Diretoria de Avaliação da Educação Superior - Daes.

Regae: Rev. Gest. Aval. Educ. Santa Maria

v. 8

n. 17

Pub. contínua 2019

p. 1-15 


\section{Considerações finais}

O Sinaes e seus mecanismos de operacionalidade são elementos do processo de regulação estatal da educação superior brasileira. Todavia, é oportuno ressaltar que nem toda regulação está à serviço dos interesses públicos, assim como não está, necessariamente, para a constituição de um mercado competitivo, contudo, os elementos que condicionam a lógica do Sinaes, em especial do Enade se mostram como verdadeiras condicionalidades da regulação para o mercado educacional.

Concernente ao aparato regulatório, Nunes, Ribeiro e Peixoto (2007) compreendem que este foi engendrado para solucionar os defeitos do mercado, "pode tornar-se, ele mesmo, uma espécie de mercado onde regulação é comprada e vendida" (p. 5). Nesse sentido, diversas foram as modificações sofridas pelo Sinaes desde sua implantação. Um programa que se sustentava na concepção de que todas as avaliações no âmbito da educação superior, realizadas pelo MEC, fossem sistematizadas e realizadas dentro de uma concepção que articulasse os momentos, metodologias, os instrumentos de avaliação e os espaços.

A partir do exposto, compreende-se que o Sinaes passou por uma inversão de sua lógica primaz. Quando implantado, a autoavaliação deveria ser o elemento conclusivo para demais modalidades da avaliação, daí seria possível julgar os elementos necessário do processo de avaliação. Todavia, o exame de desempenho obteve centralidade no processo avaliativo além da própria regulação. $O$ destaque dado ao Enade aos marcos regulatórios que condicionam o modus operandi das IES brasileiras caracterizam como um modelo de accountability.

A noção de accountabily está imbuída na lógica do Sinaes, não obstante Lacerda, Ferri e Duarte (2016) se contraporem essa noção, os autores compreendem que esse sistema de avaliação se configura como um modelo futuro de accountability. Todavia, eles próprios reconhecem que a noção de prestação de contas é nítida quando são publicados - CPC dos cursos e o IGC das IES o que, consequentemente, constituirá os rankings entre as IES tendo em vista o desempenho. Essa lógica é suplementada pela concessão de bolsas do Prouni para as IES que atingem o conceito de curso 3. Nessa acepção, evidencia-se a lógica da premiação em decorrência dos resultados que em nada deixam explícitos o conceito de qualidade.

O Sinaes se apresenta como um processo complexo dentro de circuitos de períodos temporais em que este sistema sofreu modificações de sua centralidade, inclusive. No atual período, a centralidade do exame de desempenho trata-se de ser base para os marcos regulatórios das IES, e a decorrente constituição de rankings por meio dos resultados divulgados pelo IGC. Indicadores e parâmetros para a avaliação numa fase classificatória, comparativa e escalonal são elementos que constituem a lógica da avaliação educacional, contudo, o Sinaes utiliza esses critérios sem definir precisamente o sentido de qualidade que pretende melhorar. Nessa acepção, compreende-se que é preciso sistematizar bases para questionar a processualidade do Sinaes, bem como sua lógica de accountability, e levar a cabo o debate da necessidade de constituir um sistema de avaliação da educação superior em que suas bases sejam construídas pela participação popular, em que respeite a complexidade das relações humanas, bem como as reflexões, vivências e juízos de valores historicamente acumulados pelos indivíduos. 


\section{Referências}

AFONSO, Almerino Janela. Estado, mercado, comunidade e avaliação: esboço para uma rearticulação crítica. Educação \& Sociedade, v. 20, n. 69, 1999, p. 139-164. Disponível em http://www.scielo.br/scielo.php?pid=S0101-

73301999000400007\&script=sci abstract\&tlng=pt. Acesso em 16 jul. 2017.

BOADFOOT, Patricia. Um nouveau mode de régularion dans um système décentralisé: l'Etat évaluateur. Revue Française de Pédagogie, v.130, 2000, p. 43-55.

BRASIL. Decreto n. 5.773, de 9 de maio de 2006. Dispõe sobre o exercício das funções de regulação, supervisão e avaliação das instituições de educação superior e cursos superiores de graduação e sequenciais no sistema federal de ensino. Diário Oficial da União, Brasília, 10 maio 2006.

BRASIL. Decreto n. 3.860, de 9 de julho de 2001. Dispõe sobre a organização do ensino superior, a avaliação de cursos e instituições, e dá outras providências. Diário Oficial da União. Brasília. 9 jul. 2001.

BRASIL. Decreto n. 2.207, de 15 de abril de 1997. Regulamenta, para o Sistema Federal de Ensino, as disposições contidas nos arts. 19, 20, 45, 46 e 52, parágrafo único, 54 e 88 da lei n. 9.394, de 20 de dezembro de 1996, e dá outras providências. Diário Oficial da União. Brasília, 15 de abril de 1997.

BRASIL. Decreto n. 2.026, de 10 de outubro de 1996. Estabelece procedimentos para o processo e avaliação dos cursos e instituições de ensino superior. Diário Oficial da União. Brasília, 10 out. 1996b.

BRASIL. Lei n. 9.394, de 20 de dezembro de 1996. Estabelece as diretrizes e bases da educação nacional. Diário Oficial [da república Federativa do Brasil], Brasília, 23 dez. 1996a.

BRASIL. Lei no 10.861, de 14 de abril de 2004. Institui o Sistema Nacional de Avaliação da Educação Superior - Sinaes - e dá outras providências. Diário Oficial da União. Brasília. 14 abr. 2004.

BRASIL. Portaria normativa n. 40, de 12 de dezembro de 2007. Diário Oficial da União, Brasília, 12 dez. 2007.

BRASIL. Portaria normativa $n$. 12, de 5de setembro de 2008. Institui o Índice Geral de Cursos da Instituição de Educação Superior (ICG). Brasília: DOU, 5 set. 2008.

CANAN, Silvia Regina; ELOY, Vanessa Taís. Política de avaliação em larga escala: o ENADE interfere na gestão dos cursos? Práxis Educativa, Ponta Grossa, v. 11, n. 3, 2016, p. 621-640. Disponível em http://www.revistas2.uepg.br/index.php/praxiseducativa/article/view/8996. Acesso em 4 out. 2017.

CARNOY, Martin; LOEBB, Susanna. Dies exterbal accountability affect student outcomes? A cross-state analyses. Educational Evaluation and Policy Analysis, v. 24, n. 4, 2002, p. 305-331.

DIAS SOBRINHO, José. A avaliação da educação superior. Rio de Janeiro: Vozes, 2000.

LACERDA, Leo Lynce Valle de; FERRI, Cássia; DUARTE, Blaise Keniel da Cruz. SINAES: avaliação, accountability e desempenho. Avaliação, Campinas, v. 21, n. 3, 2016, p. 975-992. Disponível em http://www.scielo.br/scielo.php?pid=S1414-

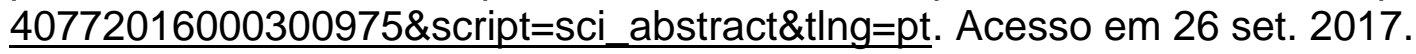


MAROY, Christian. Estado avaliador, accountability e confiança na instituição escolar. Revista Educação e Políticas em Debate, v. 2, n. 2, 2013, p. 319-338.

MAROY, Chistian. Ecole, régulacion et marché: une comparaison de six espaces scolaires em Europe. Paris: PUF, 2006.

NUNES, Edson; RIBEIRO, Leandro Molhano; PEIXOTO, Vitor. Agências regulatórias no Brasil. Rio de Janeiro: Observatório Universitário, 2007.

OLIVEIRA, Francisco. Hegemonia às avessas. In: OLIVEIRA, Francisco; BRAGA, Ruy; RIZEK, Cristina (orgs.). Hegemonia às avessas. São Paulo: Boitempo, 2010, p. 21-28.

PEREIRA, Luiz Carlos Bresser. A reforma do estado dos anos 90: lógica e mecanismos de controle (Cadernos MARE da reforma do estado; v. 1). Brasília: Ministério da Administração Federal e Reforma do Estado, 1997. Disponível em http://www.bresserpereira.org.br/documents/MARE/CadernosMare/CADERNO01.pdf.

Acesso em 1으 set. de 2017.

PINHO, José Antonio Gomes de; SACRAMENTO, Ana Rita Silva. Accountability: já podemos traduzi-la para o português? RAP (Rio de Janeiro), v. 46, n. 6,2009 , p. 13431368.

PROGRAMA DE GOVERNO DE LULA DA SILVA. Uma escola do tamanho do Brasil. 2002.

RISTOFF, Dilvo; GIOLO, Jaime. O Sinaes como sistema. RBPG, Brasília, v. 3, n. 6, 2006, p. 193-213. Disponível em http://ojs.rbpg.capes.gov.br/index.php/rbpg/article/view/106. Acesso em 2 out. 2017.

ROTHEM, José Carlos; BARREYRO, Gladys Beatriz. Avaliação, agências e especialistas: padrões oficiais de qualidade da educação superior. Ensaio: aval. pol. púlb. Educ., Rio de Janeiro, v. 17, n. 65, 2009, p. 729-751. Disponível em http://www.scielo.br/pdf/ensaio/v17n65/v17n65a10.pdf Acesso em 26 set. de 2017.

ROTHEM, José Carlos; BARREYRO, Gladys Beatriz. Percurso da avaliação da educação superior nos governos Lula. Educ. Pesqui, São Paulo, v. 40, n. 1, 2014, p. 61-76. Disponível em http://www.scielo.br/scielo.php?script=sci_arttext\&pid=S151797022014000100005. Acesso em 4 out. 2017.

SHIROMA, Eneida Oto; SANTOS, Fabiano Antonio dos. Slogans para a construção do consentimento ativo. In: EVANGELISTA, O. O que revelam os slogans na política educacional. Araraquara, SP: Junqueira \& Martins, 2014, p. 21-46.

SOUZA, Lanara Guimarães de. Avaliação de políticas educacional: contexto e conceitos em busca da avaliação pública. In: LORDÊLO, José Albertino Carvalho; DAZZANI, Maria Virgínia. (orgs.). Avaliação educacional: desatando e reatando nós. Salvador: UFBA, 2009, p. 17-29. Disponível em http://books.scielo.org/id/wd/pdf/lordelo-978852320931502.pdf. Acesso em 25 set. 2017.

Alisson Slider do Nascimento de Paula é estudante do curso de doutorado no Programa de Pós-Graduação em Educação da Universidade Estadual do Ceará e professor no Centro Universitário Inta.

Orcid: http://orcid.org/0000-0001-6356-3773.

Endereço: Avenida Paranjana, 1700 - 60740-000 - Fortaleza - CE - Brasil.

E-mail: alisson.slider@yahoo.com. 
Frederico Jorge Ferreira Costa é doutor em Educação pela Universidade Federal do Ceará e professor na Universidade Estadual do Ceará.

Orcid: http://orcid.org/0000-0002-8357-4557.

Endereço: Avenida Paranjana, 1700 - 60740-000 - Fortaleza - CE - Brasil.

E-mail: fredericoo@uece.br.

Kátia Regina Rodrigues Lima é doutora em Educação pela Universidade Federal de São Carlos e professora na Universidade Regional do Cariri.

Orcid: http://orcid.org/0000-0002-9132-9551.

Endereço: Rua Coronel Antônio Luiz Pimenta, 1000 - 63105-000 - Crato - CE Brasil.

E-mail: kareli2004@yahoo.com.

Recebido em 23 de setembro de 2018.

Aceito em 9 de novembro de 2018.

(c) (i) 